\title{
Information and Communication Technology (ICT) for Improving Quality of Health Practices
}

\author{
Pradeep Nair \\ Amity School of Communication (ASCO), Amity University (Lucknow Campus), \\ Uttar Pradesh, India
}

KEYWORDS Improving access; evidence-based practice; telemedicine; distance learning and databases and networking

\begin{abstract}
The shift in development thinking and practice towards people-centered health programmes and the participation of people and communities in decisions concerning their own health problems is creating new opportunities for ICT practices in health sector. Today, ICT is used as an empowerment tool for improving the quality of health practices in both urban and rural areas. The article looks ICT as a tool to facilitate development in health sector by encouraging dialogue and debate. The article outlines ICT as the most prominent and interactive communication method, giving voice to rural and urban people, thus enabling them to articulate their own health agendas. It is examined in the article that by fostering the exchange of knowledge and information, ICT can stimulate people's awareness and motivation, allowing them to take informed decisions on the crucial issues affecting their health.
\end{abstract}

\section{INTRODUCTION}

In the modern health environment, as in all sectors of development, knowledge and information plays a critical role. In some respects, however, the health sector's relationship with information is distinct from that of other development sectors. One aspect of this relationship is the level of knowledge and skills that physicians and other health professionals must attain - over the course of many years of study and practice in order to deliver care effectively. This is coupled with the fact that humanity's knowledge and understanding of biology and medical science is exceptionally vast making it virtually impossible for a physician to possess all the knowledge he or she might encounter. At the same time, this body of knowledge is expanding almost daily, which requires practitioners to update and maintain their skills on a regular basis - as research and best practices continually evolve.

Traditionally, health systems have tried to address these realities by promoting the concept of Continuing Medical Education (CME, also referred to as "Continuing Professional Development" or CPD) for physicians. Translated into practice, this concept typically means that

Address for correspondence: Dr. Pradeep Nair, E - II/ 99, Sector - C, Aliganj, Lucknow - 226024. Uttar Pradesh, India

Telephone: 91 - 522 - 2331224 (Residence),

Mobile: 91 - 9415788313

E-mail: pradeepnair_lu@yahoo.co.in physicians are required to demonstrate that they are keeping their skills and knowledge up-to-date by participating in periodic conferences, workshops, or courses. Over the past decade, however, information and communication technology (ICT), in particular the advent of Internet, has presented new opportunities and models for health professionals to access the most current information and update their skills - especially in countries where economic and financial conditions have prevented medical libraries from maintaining subscriptions to journals. This article will analyze some of the ways by which ICT can potentially impact the health practices in developing countries.

\section{IMPROVING ACCESS}

The ability of ICT to help improve access to information for health professionals is constrained primarily by two factors - the lack of adequate access channels for individual users and the lack of information that is both readily available and reliable. The first factor is demonstrated by the fact that the majority of health professionals in India do not have everyday access to the Internet, and very few of the health care institutions that employ them can afford to provide this access to them. This varies somewhat across the region, usually according to relative levels of economic development and urbanization. Within countries, medical universities and institutes are more likely able to provide their staff 
with access than are hospitals and polyclinics. In addition, in many developing countries budgets for state-funded health institutions are specifically earmarked, thus prohibiting health administrators from using state-provided funds for uses such as Internet connectivity. As a result, practicing physicians on the frontline of delivering primary care to the population tend to have the lowest level of access (Bhatnagar and Schware, 1994).

A variety of donor agencies (including World Health Organization, the World Bank's InfoDev Program and the UN Development Program etc.) have supported institutional access programs in India and other developing countries (Dash, 2000). One thing of all these programs have in common is the recognition of the importance of providing professionals with access as close as possible to the point of care. Given the timesensitive nature of most provider-patient interactions, it is critical for health professionals to be able to access the information they need quickly. Everyday health practitioners need to encounter several clinically important questions during the course of patient care. Without the ability to conveniently find answers to these questions, it is likely that many health professionals would not have the time to seek out the information they need (Trakroo and Lalitendu, 1992). Ideally, each physician and nurse should be able to access information in his or her own office or workstation, through a networked computer or even a palm pilot, which many physicians in developed countries are starting to use. For health providers in India that lack the technological infrastructure to support individual access for everyone, the next best thing is to provide a central access point within the institution.

\section{BRINGING CONTENT ON-LINE}

The second factor that constrains information access is the availability of reliable information. The primary sources of medical content publishers of peer-reviewed journals - generally have been reluctant to give up their revenues from print subscriptions by posting full-text articles on-line. While the U.S. National Library of Medicine has for many years been providing free on-line access to its MEDLINE database, which includes bibliographic information and abstracts for over 12 million biomedical journal articles, access to full-text articles has generally been restricted to paying subscribers at prices that are not affordable for most health care institutions in India and other developing countries.

This situation has resulted in a number of different approaches by different groups to help health professionals to find quality information on the Internet. The first of these involves working with print publishers to bring their content on-line (Dutta, 2003).

Even today, there were only a few peerreviewed research journals (including British Medical Journal and the New England Journal of Medicine) that have been willing to provide fulltext access through the Internet for free to physicians from developing countries. Over the past few years, however, efforts by international donor agencies to collectively negotiate with journal publishers to provide free access to developing countries have borne fruit. The first significant success was the result of collaboration between the Soros Foundation and EBSCO publishing. In 1999, they together launched the Electronic Information for Libraries (eIFL) program, which provides access for libraries and other institutions in 39 countries including India to EBSCO's various databases, which contain over 5,000 full-text scientific and biomedical journals (www.eifl.net).

Similarly, the World Health Organization has been engaged since 2002 in the Health InterNetwork Access to Research Initiative (HINARI), which provides access to over 2,100 full-text journals, all of which are related to health and medicine (www.healthinternetwork.org). The HINARI program, working with a wider range of journals publishers, currently provides access to 69 countries. While institutions in many countries can obtain access to these databases for free, some countries are only eligible for discounted access at \$1,000 per year. Eligibility is based on agreements that WHO has made with the journal publishers based on the current per capita GDP in each country.

National medical libraries of developing countries have also had some success in negotiating access to full-text journals, many of them inheriting relationships established through Soros Foundation's eIFL program (www.elibrary.ru). Efforts to provide access to peer-reviewed fulltext journals represent the most significant developments in improving the quality of information accessible to health professionals. 
Other activities have focused on helping health professionals to find only highest-quality content among the information being made available online (Patnaik and Saravanan, 1999).

While the Internet has made possible a remarkable growth in the amount of health-related content and information freely available to any user with a connection, it has also led to a reduction in the reliability of this information. Since anyone with access to a Web server can post something on-line, there is a risk that someone could post false or misleading information that might then be used by a health professional or a patient, with, at best, ineffective results. For example, many pharmaceutical companies trying to sell drugs or untested therapies directly to the public produce their own research that shows the effectiveness of using their drug, when unbiased, peer-reviewed research may show quite opposite. It is therefore important for providers of Web-based health content to make an effort to provide some sort of quality control for their content. One international effort to help the Internet to police itself is represented by the Health on the Net Foundation, which has developed a code of conduct for providers of health information on the Internet. This is a self-regulating effort based on the general principle of providing complete information about the source and reliability of health information (Mark, 2003).

\section{EVIDENCE-BASED PRACTICE}

The quality control issue mentioned above in this article is one aspect of the larger issue raised when providing health professionals with access to a much wider range of information. There is an enormous body of medical research available, and much of it is out-of-date and contradictory. Health professionals need to have a specific set of skills in order to assess the different types of clinical research they find and determine if and how the results of this research can be applied to a particular patient or case. Providing a framework for addressing these problems is the essence of "evidence-based practice" (EBP), also referred to as evidence-based medicine and evidence-based health care. This principle of EBP first came into prominence more than a decade ago as researchers and policy-makers discovered that a remarkably high percentage of therapies and procedures used by physicians in the West were not in compliance with the most current standards of practice. Advocates of EBP felt that by providing health professionals with the skills needed to critically evaluate clinical research articles and apply this to their practice, they would be able to improve the quality and effectiveness of health care.

In brief, EBP involves giving health professionals a deeper understanding of the different types of clinical research so that they can better evaluate its quality. It provides a step-by-step process which helps physicians to -

1. Properly formulate an answerable question to a problem,

2. Find the evidence they need,

3. Critically appraise that evidence,

4. Integrate this evidence into the physicianpatient encounter, and then

5. Evaluate the effectiveness of this process.

As a subject, EBP is now becoming part of the standard medical education curriculum at a growing number of medical universities and institutions around the world. The majority of currently practicing health professionals, however, still lacks a basic understanding of these principles.

While evidence-based practice is not strictly an ICT-related topic, it is important for organizations and groups involved with ICT projects in the health sector to consider the need to provide this type of framework for health professionals. Simply providing health professionals with greater access to information may do more harm than good if physicians simply feel inundated with information that they do not know if they can trust (Singh, 2002).

\section{TELE-MEDICINE}

Even with full access to medical information resources, physicians sometimes encounter patients whom they are unsure how to diagnose or treat. In cases like these, ICT can provide an opportunity to seek advice from a much larger field of professionals once they have exhausted the possibilities available within their institutions and local communities. Telemedicine can be especially useful for rural and underserved areas, where there are fewer specialists or perhaps only auxiliary health workers available on a full-time basis (Reddy et al., 2000).

Telemedicine provides the opportunity for clinicians to provide consultation directly to other physicians or to patients in remote areas using a wide range of technologies, including telephone, 
e-mail, and video-conferencing. These technologies enable ongoing dialogue as well as the exchange of data and clinical images such as Xrays or CT Scans.

Establishing telemedicine capabilities within a health care institution can be either low-cost or expensive, depending on the specific capabilities required. For a primary health centre, a standard consumer scanner and a dial-up Internet connection may be sufficient for the occasional consultation. For staff at a women's health centre wanting to send mammograms electronically, a high-powered scanner coupled with a high-speed connection (Broadband) may be required in order to produce and transmit digital images of sufficient resolution for clinical evaluation.

One of the difficulties with telemedicine is finding other health professionals willing to provide a consultation. Given the legal and liability concerns, many physicians in the West are often reluctant to provide detailed advice for specific patients. There are a variety of Web sites offering tele-consultations from physicians. WebMD, for example, provides the opportunity to post questions in an on-line discussion forum and their affiliated specialists will reply. Another option is to join an Internet discussion list made up of other health professionals in the same medical field and post a query requesting advice (www.webmd.com).

\section{DISTANCE LEARNING}

Much like telemedicine, distance learning can be implemented in a number of different ways using a wide range of technologies. Distance learning is defined as simply education that is delivered remotely, i.e. when the instructor and the student are not at the same location. For health professionals, this might include university-based certificate programs, CME courses, or self-directed learning modules. Information and Communication technologies are ideally suited to supporting delivery of distance learning content. The most successful programs integrate a combination of delivery methods including on-line (e-mail and Web), CD-ROM, Video (TV/VCR), audiotapes, and video-conferencing to accommodate the different capabilities and needs of the intended users.

\section{HEALTH PROMOTION}

Improving health care involves not only improving the knowledge and skills of medical professionals, but also empowering people with the knowledge needed to make informed decisions about how to live more healthy (Hiramani and Sharma, 1992). Here, too, ICT offers a plethora of alternatives to communicating important health messages to the public. While the Internet provides an easy and important opportunity to target the growing on-line community, in most developing countries, including India, radio and television provide the ability of reach to a much wider audiences.

\section{DATABASES AND NETWORKING}

In most countries of Asia, the majority of health institutions are poorly financed and thus have limited ICT resources. This economic reality has kept many health care providers from taking advantages of the benefits that ICT can offer. For example, the introduction of computerized databases can help physicians, nurses, and administrators to access clinical information about their patients as well as financial and administrative data. This helps physicians, nurses, and administrators to evaluate aggregate data about costs and the effectiveness of patient treatments.

Given the general lack of ICT infrastructure, it is difficult for most health care institutions in India to implement complex information systems. However, many of the donor health projects have provided limited support for ICT development by, for example, helping to establish local area networks, developing specialized computer software for monitoring disease outbreaks or patient records, or investing in the telecommunications infrastructure. Within these types of projects, which are usually over a short-term period, it is important for both donor and recipient organizations to try to develop a longer-term vision for the use of ICT within the institution so that short-term investments can become the building blocks for a more complex ICT infrastructure.

\section{CONCLUSION}

This article has covered a wide range of areas in which ICT can support improvements in the quality of health care. Most significantly, ICT is uniquely positioned to make a difference by helping to increase the qualifications and skills of health and medical professionals and thereby improve the delivery of health services. In the 
vast world of health and medical information, almost every place can be considered to be remote. No one has access to all of the relevant information on a particular topic, and this is where ICT can make the greatest difference. One caveat, however, is that access to information may not be sufficient in and of itself. Health professionals need to gain an understanding of how to evaluate, interpret, and apply this information to their specific practice. The principles of evidencebased practice provide a logical framework to help deal with these complexities.

ICT can also be instrumental in helping the public to become more informed about their health and how to be healthy, though until a greater percentage of the population is on-line and technologically literate, low-tech solutions are likely to be more effective.

Finally, Information and Communication Technologies can play a powerful role in improving the efficiency of health services. Through computer-based records and other technological infrastructure-building, health care institutions can better manage and share information, thereby improving the efficiency of the health system as a whole.

\section{REFERENCES}

Bhatnagar, Subhash and Robert Schware. 1994. Information and Communication Technology in Development: Cases from India. New Delhi: Sage, pp. 18-26.

Dash, S. Shefali. 2000. "Information Technology and It's Application." Yojana, 44: 11-14.

Dutta, Subrat. 2003. "Impact of Information and Communication Technology on Society." Yojana, 47: 23-32.
Hiramani, A.B. and Neelam Sharma. 1992. "Health Communication in India: A Policy Perspective", (pp. 262-263) in S. R. Mehta (ed.) Communication and Development: Issues and Perspectives. Jaipur: Rawat Publications

Patnaik, Satayanarayana and A. Saravanan. 1999. "Internet in India: An Overview." Yojana, 43: 43-45.

Reddy, Jagan Mohan, Jayashankar G. Perumal and B.S.S. Gupta. 2000. "Towards Global Village - Internet." Yojana, 44: 18-22.

Singh, Nirvikar. 2002. "IT as an Engine of Broad-based Growth in India", (pp. 37-44) in Parthasarathi Banerjee and Frank Jurgen Richer (eds.) The Information Economy in India. New York: Macmillan.

Story, Mark. 2003. "Medical Informatics and Computer Applications: Recommended Core Educational Guidelines for Family Practice Residents." Family Practice Management, 23 (4). Retrieved 10 March, 2006 from http://www.aafp.org/fpm/0996fpm/ mediinfo.html.

Trakroo, P.L. and Lalitendu Jagatdeb. 1992. "Some Issues of Development Communication in Health and Family Welfare", (pp. 243-44), in S.R. Mehta (ed.) Communication and Development: Issues and Perspectives. Jaipur: Rawat Publications.

http://www.eifl.net. (The website consists information regarding electronic information for Libraries (eIFL) program, which provides access for medical libraries and other medical and health institutions in 39 countries to EBSCO's various databases, which contain over 5,000 full text scientific and biomedical journals).

http://www.healthinternetwork.org. (the website of WHO and Health InterNetwork Access to Research Initiative (HINARI), which provides access to over 2,100 full text journals related to health and medicine).

http://www.elibrary.ru. (website of Russian Foundation for Fundamental Research consisting information and access to nearly 2,000 medical and scientific journals and databases through the web).

http://www.webmd.com (The website provides the opportunity to post questions in an on-line discussion forum and the consultants affiliated with the website will reply). 